\title{
Programmable shunts and headphones: Are they safe together?
}

\author{
Heather S. Spader, MD, ${ }^{1}$ Linda Ratanaprasatporn, MD, ${ }^{1}$ John F. Morrison, MD, ${ }^{1}$ \\ Jonathan A. Grossberg, MD, ${ }^{2}$ and G. Rees Cosgrove, MD, FRCSC ${ }^{1}$ \\ 1Department of Neurosurgery, Rhode Island Hospital and Alpert Medical School at Brown University, Providence, Rhode Island; \\ and ${ }^{2}$ Department of Neurosurgery, Emory University, Atlanta, Georgia
}

\begin{abstract}
OBJECT Programmable shunts have a valuable role in the treatment of patients with hydrocephalus, but because a magnet is used to change valve settings, interactions with external magnets may reprogram these shunts. Previous studies have demonstrated the ability of magnetic toys and iPads to erroneously reprogram shunts. Headphones are even more ubiquitous, and they contain an electromagnet for sound projection that sits on the head very close to the shunt valve. This study is the first to look at the magnetic field emissions of headphones and their effect on reprogrammable shunt valves to ascertain whether headphones are safe for patients with these shunts to wear.
\end{abstract}

METHODS In this in vitro study of the magnetic properties of headphones and their interactions with 3 different programmable shunts, the authors evaluated Apple earbuds, Beats by Dr. Dre, and Bose QuietComfort Acoustic Noise Cancelling headphones. Each headphone was tested for electromagnetic field emissions using a direct current gaussmeter. The following valves were evaluated: Codman Hakim programmable valve, Medtronic Strata II valve, and Aesculap proGAV. Each valve was tested at distances of 0 to $50 \mathrm{~mm}$ (in 5- $\mathrm{mm}$ increments) from each headphone. The exposure time at each distance was 1 minute, and 3 trials were performed to confirm results at each valve setting and distance.

RESULTS All 3 headphones generated magnetic fields greater than the respective shunt manufacturer's recommended strength of exposure, but these fields did not persist beyond $5 \mathrm{~mm}$. By $2 \mathrm{~cm}$, the fields levels were below $20 \mathrm{G}$, well below the Medtronic recommendation of $90 \mathrm{G}$ and the Codman recommendation of $80 \mathrm{G}$. Because the mechanism for the proGAV is different, there is no recommended gauss level. There was no change in gauss-level emissions by the headphones with changes in frequency and amplitude. Both the Strata and Codman-Hakim valves were reprogrammed by direct contact (distance $0 \mathrm{~mm}$ ) with the Bose headphones. When a rotation component was added, all 3 headphones reprogrammed the Strata and Codman-Hakim valves at $0 \mathrm{~mm}$. At all distances above $0 \mathrm{~mm}$, the headphones did not affect the shunts. The proGAV valve was not affected by headphones at any distance.

CONCLUSIONS Although all the headphones studied generated significant gauss fields at distances less than $5 \mathrm{~mm}$, the programmable valve settings only changed at a distance of $0 \mathrm{~mm}$ (i.e., with direct contact). Given the subcutaneous location of the valve, the authors conclude that is highly unlikely that commercially available or customary headphones can contribute to the reprogramming of shunts.

http://thejns.org/doi/abs/10.3171/2015.1.PEDS14400

KEY WORDS shunt; magnet; programmable valve; headphone; hydrocephalus

$\mathrm{T}$ HE use of programmable shunt valves has become common in the treatment of hydrocephalus because of their cost effectiveness, the ease of adjustment of ventricular drainage pressure, and a possible decreased need for surgical revision. ${ }^{3}$ Despite these benefits, however, programmable shunt valves have their own issues, including jamming, mechanical failure, and erroneous reprogramming. ${ }^{1}$
Because the valves in these shunts are programmed or reset at the bedside with a programming tool that contains a strong external fixed magnet, they are prone to accidental resetting by exposure to strong external magnetic fields. The danger of magnets in electronic devices for patients with programmable shunts has been shown in previous studies with magnetic toys and iPads. ${ }^{7,9}$ Other devices may result in similar erroneous reprogramming. Sales of 
headphones in the United States nearly doubled from 2010 to $2011 .{ }^{5,6}$ Given the ubiquity of headphones and the strong electromagnetic field they can emit, and because the valve is much closer to the headphone than to an $\mathrm{iPad}$, the issue of whether headphones would affect a programmable shunt is important.

The purpose of this study was to determine the effect of headphones on programmable shunt valve settings. We performed an in vitro study to determine whether the valve pressure settings of 3 commonly used programmable valves could be altered by exposure to headphones and, if so, at what distance.

\section{Methods}

This was an in vitro study of headphone magnetic field strengths and their interactions with programmable shunts. The set-up did not allow for the placement of a tissue layer over the valve to mimic the properties of skin. Magnetic field strength was measured using a direct current (DC) gaussmeter (Model ST, AlphaLab, Inc.). Three different headphones were evaluated: Apple earbuds, Beats by Dr. Dre, and Bose QuietComfort Acoustic Noise Cancelling headphones. The magnetic field strength emanating from the center of each headphone was measured at different distances from the headphone, starting at $0 \mathrm{~mm}$ and going up to $50 \mathrm{~mm}$ in increments of $5 \mathrm{~mm}$. Each headphone was tested 3 times. Multiple headphones and valves were not tested, but it was believed that the quality control processes in place at each manufacturing site would provide a degree of internal consistency. The electromagnetic field strength at each distance was obtained by calculating an average of these 3 trials.

The effect of the magnetic field emanating from each headphone was tested on the following 3 programmable shunt valves: Codman Hakim programmable valve, Medtronic Strata II valve, and Aesculap proGAV. The valves were exposed to each headphone at distances of 0 , $5,10,15,20$, and $50 \mathrm{~mm}$. The distance was determined by a ruler, and the valves and headphones were held manually at the designated distances. Each valve exposure to the headphone electromagnetic field lasted 1 minute. Following exposure, the valve setting was investigated, and the postexposure valve setting level was recorded. Five exposures were made at each shunt setting and distance. Next, to simulate the torque produced when putting on and taking off a headphone (in terms of magnetic field), each valve was tested with each headphone at the above distances, but the exposure included rotation of the headphones $180^{\circ}$ to the right and $180^{\circ}$ to the left for 5 trials.

Lastly, each valve and headphone combination was tested at each distance with a sustained tone frequency of $20,500,1000$, and $2000 \mathrm{~Hz}$ for 1 minute for 5 trials to see whether different frequencies affected the valve setting differently.

\section{Results}

The electromagnetic flux densities (in gauss) of the 3 headphones at different distances are shown in Table 1. As expected, the gauss level of emission decreased precipitously with increasing distance. All 3 headphones generated significant gauss fields at $0 \mathrm{~mm}$. The maximum
TABLE 1. Highest gauss level emission of headphones at various distances in 3 trials*

\begin{tabular}{lcrrrrc}
\hline & \multicolumn{7}{c}{ Distance $(\mathrm{mm})$} \\
\cline { 2 - 7 } \multicolumn{1}{c}{ Headphone } & 0 & 5 & 10 & 15 & 20 & 50 \\
\hline Apple earbuds & 196 & 51 & 5 & 2 & 1 & 0 \\
\hline Beats by Dr. Dre & 267 & 140 & 65 & 35 & 18 & 0 \\
\hline Bose QuietComfort & 240 & 134 & 68 & 44 & 15 & 0 \\
\hline
\end{tabular}

* Data shown are levels of emission in gauss $(\mathrm{G})$.

recorded flux density of the 3 headphones was $267 \mathrm{G}$ from the Beats by Dr. Dre headphone. For all headphones, the magnetic flux decreased to less than $50 \mathrm{G}$ at $15 \mathrm{~mm}$ and less than $20 \mathrm{G}$ at $20 \mathrm{~mm}$ (Fig. 1). There were no changes in gauss levels with changes in frequency for any of the headphones (data not shown).

Changes in valve settings were noted for both the Strata and Codman-Hakim valves by direct contact at $0 \mathrm{~mm}$ with the Bose headphones, with the Strata valve changing from 1.0 to 1.5 and the Codman-Hakim from 120 to 130. At all distances greater than $0 \mathrm{~mm}$, the headphones did not affect the shunts (Table 2). The Aesculap proGAV valve was not affected at any distance.

When a rotational component was added to the testing, both the Strata and Codman-Hakim valves were reprogrammed by all 3 headphones at $0 \mathrm{~mm}$ but remained unchanged at distances of $5 \mathrm{~mm}$ and greater (Table 2). The Aesculap proGAV valve was not affected at any distance.

\section{Discussion}

The aim of this study was to assess the effect of headphones on 3 programmable valves that are widely used in the surgical treatment of hydrocephalus. To our knowledge, this is the first study of its kind. Given the fact that the sales of headphones in 2011 were greater than $\$ 2$ billion, the effect of headphones on programmable shunt valves is an important health issue for hydrocephalus patients. 5,6

In this study, we found that headphones emit a high magnetic field at $0 \mathrm{~mm}$ from the center of the headphone, but the field drops off quickly. Of note, even the

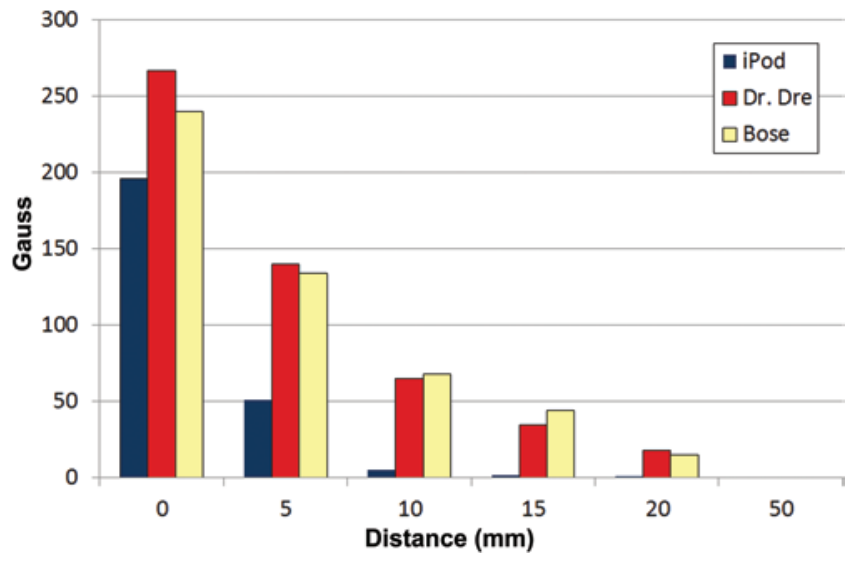

FIG. 1. Highest gauss level emissions of headphones at various distances. Figure is available in color online only. 
TABLE 2. Change in shunt setting at different distances from headphones*

\begin{tabular}{|c|c|c|c|c|c|c|c|}
\hline \multirow[b]{2}{*}{ Headphone Type } & \multirow[b]{2}{*}{$\begin{array}{c}\text { Distance } \\
(\mathrm{mm})\end{array}$} & \multicolumn{2}{|c|}{ Medtronic Strata II } & \multicolumn{2}{|c|}{ Codman-Hakim } & \multicolumn{2}{|c|}{ Aesculap proGAV } \\
\hline & & $\begin{array}{c}\text { Valve } \\
\text { Change? }\end{array}$ & $\begin{array}{l}\text { Valve Change w/ } \\
180^{\circ} \text { Rotation? }\end{array}$ & $\begin{array}{l}\text { Valve } \\
\text { Change? }\end{array}$ & $\begin{array}{c}\text { Valve Change w/ } \\
180^{\circ} \text { Rotation? }\end{array}$ & $\begin{array}{l}\text { Valve } \\
\text { Change? }\end{array}$ & $\begin{array}{c}\text { Valve Change w/ } \\
180^{\circ} \text { Rotation? }\end{array}$ \\
\hline \multirow[t]{6}{*}{ Apple earbuds } & 0 & $\mathrm{~N}$ & Y & $\mathrm{N}$ & Y & $\mathrm{N}$ & $\mathrm{N}$ \\
\hline & 5 & $\mathrm{~N}$ & $\mathrm{~N}$ & $\mathrm{~N}$ & $\mathrm{~N}$ & $\mathrm{~N}$ & $\mathrm{~N}$ \\
\hline & 10 & $\mathrm{~N}$ & $\mathrm{~N}$ & $\mathrm{~N}$ & $\mathrm{~N}$ & $\mathrm{~N}$ & $\mathrm{~N}$ \\
\hline & 15 & $\mathrm{~N}$ & $\mathrm{~N}$ & $\mathrm{~N}$ & $\mathrm{~N}$ & $\mathrm{~N}$ & $\mathrm{~N}$ \\
\hline & 20 & $\mathrm{~N}$ & $\mathrm{~N}$ & $\mathrm{~N}$ & $\mathrm{~N}$ & $\mathrm{~N}$ & $\mathrm{~N}$ \\
\hline & 50 & $\mathrm{~N}$ & $\mathrm{~N}$ & $\mathrm{~N}$ & $\mathrm{~N}$ & $\mathrm{~N}$ & $\mathrm{~N}$ \\
\hline \multirow[t]{6}{*}{ Beats by Dr. Dre } & 0 & $\mathrm{~N}$ & Y & $\mathrm{N}$ & Y & $\mathrm{N}$ & $\mathrm{N}$ \\
\hline & 5 & $\mathrm{~N}$ & $\mathrm{~N}$ & $\mathrm{~N}$ & $\mathrm{~N}$ & $\mathrm{~N}$ & $\mathrm{~N}$ \\
\hline & 10 & $\mathrm{~N}$ & $\mathrm{~N}$ & $\mathrm{~N}$ & $\mathrm{~N}$ & $\mathrm{~N}$ & $\mathrm{~N}$ \\
\hline & 15 & $\mathrm{~N}$ & $\mathrm{~N}$ & $\mathrm{~N}$ & $\mathrm{~N}$ & $\mathrm{~N}$ & $\mathrm{~N}$ \\
\hline & 20 & $\mathrm{~N}$ & $\mathrm{~N}$ & $\mathrm{~N}$ & $\mathrm{~N}$ & $\mathrm{~N}$ & $\mathrm{~N}$ \\
\hline & 50 & $\mathrm{~N}$ & $\mathrm{~N}$ & $\mathrm{~N}$ & $\mathrm{~N}$ & $\mathrm{~N}$ & $\mathrm{~N}$ \\
\hline \multirow[t]{6}{*}{ Bose QuietComfort } & 0 & Y & Y & Y & Y & $\mathrm{N}$ & $\mathrm{N}$ \\
\hline & 5 & $\mathrm{~N}$ & $\mathrm{~N}$ & $\mathrm{~N}$ & $\mathrm{~N}$ & $\mathrm{~N}$ & $\mathrm{~N}$ \\
\hline & 10 & $\mathrm{~N}$ & $\mathrm{~N}$ & $\mathrm{~N}$ & $\mathrm{~N}$ & $\mathrm{~N}$ & $\mathrm{~N}$ \\
\hline & 15 & $\mathrm{~N}$ & $\mathrm{~N}$ & $\mathrm{~N}$ & $\mathrm{~N}$ & $\mathrm{~N}$ & $\mathrm{~N}$ \\
\hline & 20 & $\mathrm{~N}$ & $\mathrm{~N}$ & $\mathrm{~N}$ & $\mathrm{~N}$ & $\mathrm{~N}$ & $\mathrm{~N}$ \\
\hline & 50 & $\mathrm{~N}$ & $\mathrm{~N}$ & $\mathrm{~N}$ & $\mathrm{~N}$ & $\mathrm{~N}$ & $\mathrm{~N}$ \\
\hline
\end{tabular}

* Gray fill indicates changes in shunt settings.

much smaller earbuds emitted a magnet field of almost 200 G. All 3 headphones reprogrammed the Codman and Medtronic valves at $0 \mathrm{~mm}$ with a rotational component. The Bose headphones reprogrammed the Codman and Medtronic valves at $0 \mathrm{~mm}$ and no rotation. No reprogramming was found for any of the valves at distances of $5 \mathrm{~mm}$ or more for any of the headphones. The headphones had no effect on the proGAV valve, even at $0 \mathrm{~mm}$.

There have been multiple previous reports of environmental magnetic field exposures changing adjustable valve settings. It has been established that magnetic resonance imaging and transcranial magnetic stimulation, which both generate high-intensity, focal magnetic fields, affect valve settings. ${ }^{2,4}$ There are precautions in place when patients are being examined or treated with these modalities to check valve settings because of the exposure to a magnetic field. Patients with hydrocephalus are also exposed to environments in their daily life that generate significant magnetic fields, but they may not know that the valve settings should be checked until a change is noted during neurological examination. Previous studies have revealed that even low-intensity magnetic fields from objects such as magnetic toys, television, and speakers can change the setting in some models of programmable valves. ${ }^{2,4,8,9} \mathrm{In}$ a recent study, the maximum gauss level produced by an iPad was $170 \mathrm{G}$, which is less than the maximum gauss level found in any of our headphones. ${ }^{7}$ Given that the magnetic field from a headphone is much closer to the valve, there is cause for concern regarding headphones.

The maximum magnetic field exposure recommended for the valves by Codman and Medtronic are 80 and $90 \mathrm{G}$, respectively (http://www.mrisafety.com/SafetyInfov.asp? SafetyInfoID=248). Therefore, the headphones still emit magnetic fields at $5 \mathrm{~mm}$ that are high enough (range 51$140 \mathrm{G}$ ) to exceed the manufacturers' warnings. In addition, $5 \mathrm{~mm}$ approaches the presumed distance between these headphones (particularly ones with large ear pieces) and the shunt valve. Although we did not see the shunts reprogrammed at a distance of $5 \mathrm{~mm}$, it is possible that with longer and repeated exposures there could be a significant risk of spontaneous programmable shunt valve reprogramming.

There are several limitations of our study. First, our magnetic exposure trials were conducted in different conditions than would be expected clinically. No attempt was made to separate the headphones and shunt valve with a tissue layer. Theoretically, this could have protective effects against changes in valve settings. Nonetheless, magnetic fields freely penetrate soft tissue such as skin. It is important to note that the headphones sit in the external auditory meatus and the valve is behind the ear. Therefore, the greatest potential for damage may be when the headphones are put on and taken off, creating a more tangential magnetic force near the valve. As this was an in vitro study, it was difficult to ascertain how this natural movement of putting headphones on and taking them off would affect the valves. Lastly, largely because of the expense, only a single valve from each of the 3 manufacturers was examined. Variability in the susceptibility of different valves cannot be ruled out. Furthermore, only 3 types of headphones among the many available were tested.

\section{Conclusions}

Neurosurgeons should be aware that the potential for shunt reprogramming in patients using headphones is re- 
mote unless a headphone is in direct contact with a programmable shunt valve or there is tangential movement of a headphone around a valve. Since most headphones do not emit any significant magnetic force beyond $5 \mathrm{~mm}$, we find no evidence that they are capable of changing a programmable valve under standard use conditions. Shunts are more likely to fail from obstruction, infection, or valve failure than from reprogramming from magnets.

\section{Acknowledgments}

The authors would like to thank Petra M. Klinge, MD, PhD, for her invaluable advice on this topic and Kristin L. Kraus, MSc, for her editorial assistance.

\section{References}

1. Bullivant KJ, Mitha AP, Hamilton MG: Management of a locked Strata valve. J Neurosurg Pediatr 3:340-343, 2009

2. Lavinio A, Harding S, Van Der Boogaard F, Czosnyka M, Smielewski P, Richards HK, et al: Magnetic field interactions in adjustable hydrocephalus shunts. J Neurosurg Pediatr 2: 222-228, 2008

3. Lee L, King NK, Kumar D, Ng YP, Rao J, Ng H, et al: Use of programmable versus nonprogrammable shunts in the management of hydrocephalus secondary to aneurysmal subarachnoid hemorrhage: a retrospective study with costbenefit analysis. J Neurosurg 121:899-903, 2014

4. Lefranc M, Ko JY, Peltier J, Fichten A, Desenclos C, Macron $\mathrm{JM}$, et al: Effect of transcranial magnetic stimulation on four types of pressure-programmable valves. Acta Neurochir (Wien) 152:689-697, 2010

5. NPD Group: Headphones priced at above $\$ 100$ account for more than $\$ 340$ million in sales through November. January 6, 2012. (https://www.npd.com/wps/portal/npd/us/news/ press-releases/pr_120106/) [Accessed April 8, 2015]
6. NPD Group: The percentage of premium headphones connected to tablets triples in 2012, according to NPD. August 13, 2012. (https://www.npd.com/wps/portal/npd/us/news/ press-releases/pr_120813/) [Accessed April 8, 2015]

7. Strahle J, Selzer BJ, Muraszko KM, Garton HJ, Maher CO: Programmable shunt valve affected by exposure to a tablet computer. J Neurosurg Pediatr 10:118-120, 2012

8. Utsuki S, Shimizu S, Oka H, Suzuki S, Fujii K: Alteration of the pressure setting of a Codman-Hakim programmable valve by a television. Neurol Med Chir (Tokyo) 46:405407, 2006

9. Zuzak TJ, Balmer B, Schmidig D, Boltshauser E, Grotzer MA: Magnetic toys: forbidden for pediatric patients with certain programmable shunt valves? Childs Nerv Syst 25:161-164, 2009

\section{Author Contributions}

Conception and design: Spader, Morrison, Grossberg. Acquisition of data: Spader. Analysis and interpretation of data: all authors. Drafting the article: Spader, Ratanaprasatporn. Critically revising the article: all authors. Reviewed submitted version of manuscript: all authors. Approved the final version of the manuscript on behalf of all authors: Spader.

\section{Supplemental Information Current Affiliation}

Dr. Ratanaprasatporn: Department of Radiology, Brigham and Women's Hospital, Boston, Massachusetts.

\section{Correspondence}

Heather S. Spader, Joe Dimaggio Children's Hospital, 1150 N. 35th Ave., Hollywood, FL 33021. email: heatherspader@gmail. com 